\title{
INTESTINAL PARASITES IN CHILDREN RECEIVING CHEMOTHERAPY
}

\section{By}

HANAA AHMED EL-HADY ${ }^{1}$, NOHA SAMMER AHMED ${ }^{1^{\star}}$, MOHAMED AHMED

ALI TAHA ${ }^{2}$, NASSER MOHAMED ABD EL-KAREEM ${ }^{2}$

AND RAFAAT ABDELAAL BAKHEET ${ }^{3}$

Department of Medical Parasitology ${ }^{1}$, Faculty of Medicine, Sohag University, Department of Medical Parasitology ${ }^{2}$, Faculty of Medicine, Al Azhar University, and De-

partment of Oncology ${ }^{3}$, Faculty of Medicine, Sohag University, Egypt.

$\left({ }^{\star}\right.$ Correspondence: nohasammer@yahoo.com)

\section{Abstract}

Serious complications associated with some parasitic diseases in immunosuppressed patients. An extreme course might be connected with noteworthy morbidity and mortal sin in children having intestinal parasitic infections and getting chemotherapy for management from threatening tumors. This study pointed at figuring out the prevalence and type of intestinal parasites over stool specimens of children receiving chemotherapy contrasted with healthy children. A cross-sectional survey was calculated among 100 children receiving chemotherapy in Sohag Oncology Institute and 100 apparently healthy children as a control group. Stool examination by direct method and concentration by formol-ether sedimentation, then staining with Kinyoun's modified acid-fast stain were done. Among those children receiving chemotherapy, 94\% were diagnosed positive for parasitic infections, in contrast to $35 \%$ in the control group. Parasites that were detected in children receiving chemotherapy and healthy control group respectively were Cryptosporidium sp.(45\% vs.10\%), Giardia lamblia (19\% vs. 7\%), Entamoeba histolytica (14\% vs. $4 \%$ ). Statistically significant differences in these parasitic infections were detected between the two studied groups (p-value $<0.001)$, while infections with Entamoeba coli (12\% vs. 4\%), Hymenolepis nana (4\% vs. 4\%), Schistosoma mansoni ( $0 \%$ to $2 \%)$ were statistically not significant. Parasitic infection is common among children receiving chemotherapy. In order to get the suitable management clinicians treating children receiving chemotherapy should make mindful about these infections.

Keywords: Children, Chemotherapy, Cryptosporidium sp., Giardia lamblia, Entamoeba histolytica.

\section{Introduction}

Children with cancer often have gastrointestinal and liver symptoms. Risk factors include neoplastic infiltration, mechanical obstruction by tumor mass, abdominal tumor rupture, abdominal surgery, radiation therapy and, primarily, antineoplastic chemotherapy, with different effects according to drugs, dosing, schedule and the associated treatments (Castagnola et $a l, 2016)$. Parasitic infections are common among children in developing countries especially the immunocompromised children (Ajjampur et al, 2008). The immunocompromised patient does not have the ability to react typically to the infection due to an impeded or the weakened immune system. The defects in the normal defense mechan- ism might predispose those people to an expanded danger for the severe life-threatening infections (Pizzo, 1996).

The different parasitic infections are associated with defects in the immune system (Weber et al, 2006). The intestinal parasites as Cryptosporidium parvum, Cyclospora, Microspora spp., Isospora spp., Giardia lamblia and Strongyloides are the most common parasites, which may cause morbidity and/or mortality in immunocompromised hosts (Noskin et al, 1997). Cryptosporidium species are apicomplexan parasites that infect the gastrointestinal epithelium. The infected people showed a wide range of the clinical presentations. However, Cryptosporidium pathogenicity varies with the parasites species included the type, age, and furthermore, immune status of the host. 
They are important, widespread causes of diarrheal ailment over people and some domesticated animals (Xiao et al, 2004).

Other types of parasites, such as Giardia lamblia, Entamoeba histolytica were also frequently detected in immunosuppressed patients (Mariam et al, 2008).

Giardia lamblia (syn. G. intestinalis or $G$. duodenalis) is a flagellated unicellular eukaryotic microorganism that commonly causes diarrheal disease worldwide. It is the most common cause of waterborne outbreaks of diarrhea in the United States (Barwick et al, 2000) and among the travelers with chronic diarrhea (Huang and White, 2006).

Amoebiasis is initiated by the discovered worldwide protozoa, Entamoeba histolyti$c a$. The highest prevalence of amoebiasis was in developing countries where barriers between human feces, food and water supplies were inadequate (Grecu et al, 2006; Pritt and Clark, 2008). On the other hand, the relationship between suppression in the immune status in children receiving chemotherapy and intestinal parasites in Sohag Governorate, Egypt has not been studied.

This study was conducted to compare the prevalence and type of intestinal parasites in the stool specimens of children receiving chemotherapy as compared to apparently healthy children.

\section{Subjects and Methods}

Study population, ethics statement and inclusion criteria: Study population was 100 children receiving chemo- therapy in Sohag Oncology Institute with aged 3-12 years old, and another one hundred apparently healthy cross-matched children as controls. They were in-formed that the aim of study was voluntary and their privacy would be protected. All the children who agreed to participate in this study and whose parents gave a written informed consent eligible for the study after being authorized by the scientific ethics committee of the institute.

Study design: The cross-sectional baseline survey assessed the prevalence and the intensity of parasitic infection among children receiving chemotherapy to that observed in apparently healthy children.

Stool collection and parasite identification: Stool samples were collected into closed sterile labeled stool containers. All samples were subjected to stool examination by direct examination, by formol-ether sedimentation method then stained with Kinyoun's modified acid-fast stain (Cheesbrough, 2009). Each slide was carefully examined under x40 \& x100 magnification. Children were considered positive for a particular infection if at least one of the diagnostic methods revealed a positive result.

Statistical analysis: Statistical Package for Social Science (SPSS) program (version 20) was used for grouping, tabulation and analysis of data. Sample characteristics were given using mean standard deviation (SD) for continuous variables and percentage for categorical variables. Difference in prevalence of intestinal parasites between groups was evaluated by chi-square test. $\mathrm{P}$ value below 0.05 was considered significant.

\section{Results}

Sociodemographic characteristics of studied participants: 200 children were enrollled in this study, including 109 boys and 91 girls, there was no significant difference between boys and girls (54.5\% vs. $45.5 \%)$ respectively. Stool samples were collected from 100 children on chemotherapy at Sohag Oncology Institute as a study group aged 3 to 12 years $($ age $=8.9 \pm 1.9)$ and from 100 apparently healthy children as a control group (age $=10.7 \pm 0.4$ ).

The parasites in patients and controls were oocysts of Cryptosporidium spp. positive (27\%), cysts of Giardia lamblia positive (13\%), trophozoites and cysts of Entamoeba coli positive (11\%), cysts of Entamoeba histolytica positive (9\%), Hymenolepis nana eggs positive (4\%) and Schistosoma mansoni positive (1\%) in groups (Tab. 1). 
Table 1: Sex and variable distributions of intestinal parasitic infections among samples.

\begin{tabular}{|l|l|c|c|}
\hline \multicolumn{2}{|c|}{ Variable } & No. $(\mathrm{N}=200)$ & $\%$ \\
\hline \multirow{2}{*}{ Sex } & Boys & 109 & $54.5 \%$ \\
\cline { 2 - 4 } & Girls & 91 & $45.5 \%$ \\
\hline \multirow{2}{*}{ Chemotherapy } & Yes & 100 & $50.0 \%$ \\
\cline { 2 - 4 } & No & 100 & $50.0 \%$ \\
\hline \multirow{2}{*}{ G. lamblia } & Positive & 55 & $27.0 \%$ \\
\cline { 2 - 4 } & Negative & 145 & $73.0 \%$ \\
\hline \multirow{3}{*}{ E. histolytica } & Positive & 26 & $13.0 \%$ \\
\cline { 2 - 4 } & Negative & 174 & $87.0 \%$ \\
\hline \multirow{2}{*}{ E. coli } & Positive & 18 & $9.0 \%$ \\
\cline { 2 - 4 } & Negative & 182 & $91.0 \%$ \\
\hline \multirow{2}{*}{ H. nana } & Positive & 22 & $11.0 \%$ \\
\cline { 2 - 4 } & Negative & 178 & $89.0 \%$ \\
\hline \multirow{2}{*}{ S. mansoni } & Positive & 8 & $4.0 \%$ \\
\cline { 2 - 4 } & Negative & 192 & $96.0 \%$ \\
\cline { 2 - 4 } & Positive & 2 & $1.0 \%$ \\
\hline
\end{tabular}

The parasitic infections in children on 10\%), G. lamblia (19\% vs.7\%), E. histochemotherapy and controls separately: 94 lytica (14\% vs. 4\%) were significant betchildren (94\%) were diagnosed positive for ween both groups $(\mathrm{p}<0.001)$. E. coli parasitosis among children on chemothera- (12\% vs. $4 \%)$, H. nana (4\% vs. $4 \%$ ) and $S$. py, whereas 35 children $(35 \%)$ were posi- mansoni (0\% vs. $2 \%$ ) were without signifitive in controls. Parasites ldetected in child- cant between both groups (Tab. 2). Distriburen on chemotherapy and controls respecti- tion of parasitic infection among patients vely were Cryptosporidium sp. (45\% vs. and controls was given (Fig. 1).

Table 2:Prevalence of parasitic infections between children receiving chemotherapy and control group.

\begin{tabular}{|c|c|c|c|c|c|c|}
\hline \multirow{2}{*}{ Parasitic infection } & \multirow{2}{*}{ Result } & \multicolumn{2}{|c|}{ Chemotherapy group $(\mathrm{N}=100)$} & \multicolumn{2}{|c|}{ Control group $(\mathrm{N}=100)$} & \multirow[t]{2}{*}{$\mathrm{P}$ value } \\
\hline & & No. & $\%$ & No. & $\%$ & \\
\hline \multirow{2}{*}{ Cryptosporidium } & $+\mathrm{ve}$ & 45 & $45 \%$ & 10 & $10 \%$ & \multirow[b]{2}{*}{$P<0.001 *$} \\
\hline & - ve & 55 & $55 \%$ & 90 & $90 \%$ & \\
\hline \multirow{2}{*}{ G. lamblia cyst } & $+\mathrm{ve}$ & 19 & $19 \%$ & 7 & $7 \%$ & \multirow[b]{2}{*}{$P<0.001^{*}$} \\
\hline & $-\mathrm{ve}$ & 81 & $81 \%$ & 93 & $93 \%$ & \\
\hline \multirow{2}{*}{ E. histolytica cyst } & $+\mathrm{ve}$ & 14 & $14 \%$ & 4 & $4 \%$ & \multirow[b]{2}{*}{$P<0.001^{*}$} \\
\hline & - ve & 86 & $86 \%$ & 96 & $96 \%$ & \\
\hline \multirow{2}{*}{ E.coli } & $+\mathrm{ve}$ & 12 & $12 \%$ & 10 & $10 \%$ & \multirow[b]{2}{*}{$P=0.674$} \\
\hline & -ve & 88 & $88 \%$ & 90 & $90 \%$ & \\
\hline \multirow{2}{*}{ H.nana egg } & $+\mathrm{ve}$ & 4 & $4 \%$ & 4 & $4 \%$ & \multirow[b]{2}{*}{$P=0.155$} \\
\hline & - ve & 96 & $96 \%$ & 96 & $96 \%$ & \\
\hline \multirow{2}{*}{ S. mansoni egg } & $+\mathrm{ve}$ & 0 & $0 \%$ & 2 & $2 \%$ & \multirow[t]{2}{*}{$P=1.000$} \\
\hline & $-\mathrm{ve}$ & 100 & $100 \%$ & 98 & $98 \%$ & \\
\hline
\end{tabular}

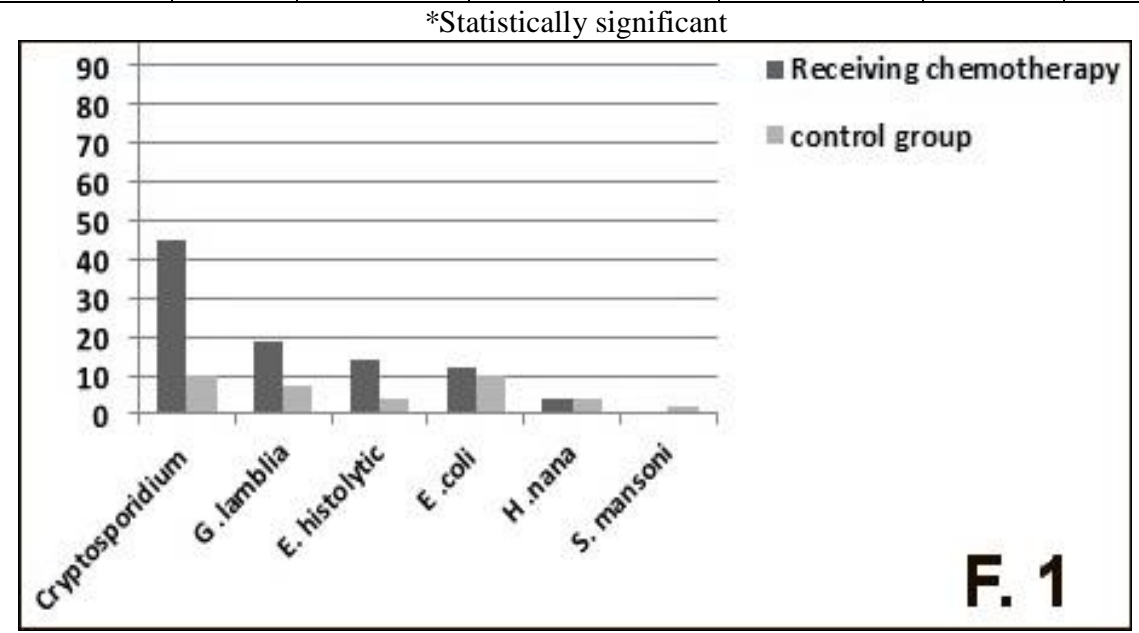

Fig. 1: Distribution of parasitic infection among children receiving chemotherapy and control group 


\section{Discussion}

Intestinal parasites are the majority basic human infections distributed world- wide with high pervasiveness rates in the developing countries (Sethi et al, 2000). A lot of these pathogens, especially the intra- cellular protozoa that chiefly influence the small intestine, produce their most devastating effects in patients with immune defi- ciency. Parasitic infections generally are asymptomatic in otherwise healthy indivi- duals; however, their manifestations in immunocompromised individuals were more severe and tend to produce greater pathological sequelae in these patients (Garcia, 2001). With the increasing numbers of the immunocompromised individuals worldwide, closer examination and detection of intestinal parasitic infections in these individuals is highly needed (Kamki et al, 2015).

In the present study, the overall parasitic infection was $94 \%$ among the immunocompromised group and in 35\% among healthy control group. This result agreed with Abdel-Hafeez et al. (2012) who detected $94 \%$ intestinal parasites positivity among the immunosuppressed patients, and 60\% among the immunocompetent ones.

El-Nadi and Taha (2004) reported 94\% among the immunocompromised patients had parasitic infections. But, Khalil et al. (1991), Abaza et al. (1995) and El- Diffrawy et al. (2002) reported parasitic infections rates of $18.9 \%, 23 \%, \& 48 \%$ respectively among the immunocompromised patients. The difference in parasitic prevalence may be due to multifactorial reasons as environment and climatic conditions, sanitary practices and the different sample size and ages.

In the present study, Cryptosporidium was the commonest in both groups (45\% vs. $10 \%)$. Establishment of some organisms may follow the reduction in the local and cell-mediated responses to intestinal parasites in immunosuppressed patients. This data agreed with Abdel-Hafeez et al. (2012) who found that prevalence of cryptospori- diosis was higher in the immunosuppressed group than the immunocompetent ones (60.2\% vs. $42.2 \%)$.

In the present study, both G. lamblia and $E$. histolytica were more prevalent in patients with immunosuppressed status than in immunocompetent status (19\% vs. $7 \%$ \& $14 \%$ vs. $4 \%$ ) respectively, but less than Cryptosporidium. Some changes in the gut structure may follow infection in immunosuppressed patients, which were unsuitable for E. histolytica and G. lamblia establishment (Abdel-Hafeez et al, 2012). Intestinal parasites colonization might be induced by any enteropathy cause(s), which suppressed of immunity (McMurchy et al, 2010). Also, this may selectively determine the establishment and/or survival of extra-cellular and luminal parasites. In contrast, whereas gut of immunosuppressed people might not make ideal surroundings to the establishment also or survival of extra-cellular parasites, mucosal staying creatures might not be adversely influenced toward those pathologic transforms (Lindo et al, 1998) or may be due to immune response in giardiasis is principally humoral and the role of cellular immunity is questionable in man-kind's (Lewis et al, 1997). Stevenson (1987) in patients on the chemotherapy, found suppression of antibody production and avoidance of multiplication of stimulated B-cells happened. El-Nadi and Taha, (2004) among immunosuppressed patients found that $E$. histolytica and $G$. lamblia were $56 \%$ \& 58\%. Abdel-Hafeez et al. (2012) found that E. histolytica and G. lamblia were prevalent in immunocompetent patients than in immunosuppressed ones $(24.6 \%$ vs. $6 \%$ \& $17.6 \%$ vs. $4.8 \%$ ) respectively.

In the present study, E. coli was more prevalent in immunosuppressed patients than in immunocompetent ones (12\% vs. $10 \%$ ), without significant. This agreed with Cimerman and Lewis (1999) in Brazil and Assefa et al. (2009) in Ethiopia found that E. coli was $13 \% \& 12.6 \%$ respectively but 
more prevalent than that of Mohandas et al.(2002) in North India and Al-Megrin (2010) in Saudi Arabia who reported E. coli $1.7 \%$ \& $3.7 \%$ respectively.

In the present study, $H$. nana prevalence was $4 \%$ in both the immunosuppressed patients and the controls. El Nadi and Taha (2004) found no difference in $H$. nana in both groups, but Zabolinejad et al. (2013) in Iran reported $(1.1 \%)$ pervasiveness of $H$. nana in youngsters with malignancy. Generally, $H$. nana is transmitted by autoinfection without related to patient immunity

In the present study, $S$. mansoni was more prevalent in immunocompetent patients than in immunosuppressed status (2\% vs. $0 \%$ ), which might be due to the fact that the immuno-suppressed children on chemotherapy did not play in the canals' water as the healthy children. In the present study, none in both groups had S. stercoralis. AbdelHafeez et al. (2012) found none with $S$. stercoralis, but Mariam et al. (2008) found that $S$. stercoralis was $11.5 \%$. Also, none had Microsporidia, or Cyclospora, or Isospora. But, El-Diffrawy et al. (2002) found Cyclospora (8\%), and Baiomy et al, (2010) detected Microsporidia (2\%) among immune-compromised patients. This might be due to differences in environment, climates social, health, and/or economic conditions.

\section{Conclusion}

The parasitic infection is common among children receiving chemotherapy. The present study highlights the importance of searching for intestinal parasites in the immunocompromised children and emphasizes the necessity awareness among the clinicians regarding occurrence of parasites in this population and health education for food hygiene. Recurrence also risk for these parasitic infection required their proficient diagnosis and proper management.

\section{References}

Abaza, SM, Makhlouf, LM, El-Shewy, KA, El-Moamly, AA, 1995: Intestinal opportunistic parasites among different groups of immunecompromised hosts. J. Egypt. Soc. Parasitol. 25, 3:713-27.
Abdel-Hafeez, EH, Ahmad, AK, Ali, BA, Muslim, FA, 2012: Opportunistic parasites among immunosuppressed children in Minia District, Egypt, Korean J. Parasitol. 50, 1:57-62.

Ajjampur, SS, Sankaran, P, Kang, G, 2008: Cryptosporidium species in HIV-infected individuals in India: an overview. Natl. Med. J. India. 21, 4:178-84

Al-Megrin, WAI, 2010: Intestinal parasites infection among immunocompromised patients in Riyadh, Saudi Arabia. Pakis. J. Biol. Sci. 13:390-4.

Assefa, S, Erko, B, Medhin, G, Assfa, Z, Shimelis, T, 2009: Intestinal parasitic infec-tions in relation to HIV/AIDS status, diarrhea and CD4 T-cell count, BMC Infect. Dis. 9:155-9.

Baiomy, AM, Mohamed, KA, Ghannam, MA, Shahat, SA, Al-Saadawy, AS, 2010: Opportunistic parasitic infections among immuno-compromised Egyptian patients. J. Egypt. Soc. Parasitol. 40, 3:797-808.

Barwick, RS, Levy, DA, Braun, GF, Beach, MJ, Calderon, RL, 2000: Surveillance for water-borne-diseases' outbreaks United States, 1997-1998. Morb. Mortal. Wkly. Rep. CDC Surveill. Summ. 49 (SS-4):1-36.

Castagnola, E, Ruberto, E, Guarino, A, 2016: Gastrointestinal and liver infections in children undergoing antineoplastic chemotherapy in year 2000. Wld. J. Gastroenterol. 22, 25:585366.

Cheesbrough, M, 2009: District Laboratory Practice in Tropical Countries, Part I. $2^{\text {nd }}$ ed. Cambridge: Cambridge University Press.

Cimerman, B, Lewis, DS, 1999: Prevalence of intestinal parasitic infection in patients with acquired immunodeficiency syndrome in Brazil. Int. J. Infect. Dis. 3, 4:203-6.

El-Diffrawy, M, Neanaa, H, Eissa, M, Sadaka, H, Nomir, A, 2002: Study of parasitic infections in immunocompromised patients in Haematology Department at Main University Hospital Report, Alexandria, 5-10.

El-Nadi, NA, Taha, A, 2004: Intestinal parasites detected among haemodialysis-patients in Sohag University Hospitals. El Minia. Med. Bull. 15:2-8.

Garcia, LS, 2001: Diagnostic Medical Parasitology, $4^{\text {th }}$ Edn. Washington DC: ASM Press Grecu, F, Bulgariu, T,Blanaru, O, Dragomir, C, Lunca, C, et al, 2006: Invasive amoebiasis. Chirurgia 101:539-42.

Huang, DB, White, AC, 2006: An updated re- 
view on Cryptosporidium and Giardia. Gastroenterol. Clin. North Am. 35, 2:291-314. Kamki, Y, Singh, RH, Singh, NT, Lungram, P, Singh BN, 2015: Intestinal protozoa and helminthic infections in immunocompromised patients attending RIMS Hospital. Imphal. 29, 2:74-8.

Khalil, HM, Makled, MK, Azab, ME, Abdalla, HM, Sherif, EA, et al, 1991: Opportunistic parasitic infection in immunocompromised hosts. J. Egypt. Soc. Parasitol. 21, 3:657-66.

Lewis, PD, Belosevic, M, Faubert, GM, Gurthoys, L, MacLean, JD, 1997: Cortisone induced recrudescence of $G$. lamblia infections in Gerbils. Am. J. Trap. Med. Hyg. 36, 1: 33-6.

Lindo, JF, Dubon, JM, Ager, AL, de Gourville, EM, Solo-Gabriele, H, et al, 1998: Intestinal parasitic infections in human immuno- deficiency virus (HIV)-positive \& HIV-negative individuals in San Pedro Sula, Honduras. Am. J. Trop. Med. Hyg. 58:431-5.

Mariam, ZT, Abebe, G, Mulu, A, 2008: Opportunistic and other intestinal parasitic infections in AIDS patients, HIV seropositive healthy carriers and HIV seronegative individuals in southwest Ethiopia. East. Afr. J. Publ. Hlth. 5:169-73.

McMurchy, AN, Gillies, J, Allan, SE, Passerini, L, Gambineri, E, et al, 2010: Point mutants of forkhead box P3 that cause immune dysregulation, polyendocrinopathy, enteropathy, $\mathrm{X}$ linked have diverse abilities to reprogram $\mathrm{T}$ cells into regulatory T cells. J. Allergy Clin. Immunol. 126, 6:1242-51.

Mohandas, Sehgal, R, Sudde, A, Malla, DN,
2002: Prevalence of intestinal parasite pathogens in HIV-seropositive individual in northern India. Jpn. J. Infect. Dis. 55:83-4.

Noskin, GA, Phair, JP, Murphy, RL,1997: Diagnosis and management of infection in the immunocompromised host. In: Shulman, Phair, Peterson, Warren, EDS. Infectious Diseases $5^{\text {th }}$ ed. Philadelphia: WB Saunders.

Pizzo, PA, 1996: The compromised host. In: Bennett and Plums EDS. Cecil's Textbook of Medicine. WB Saunders, New York.

Pritt, BS, Clark, CG, 2008: Amoebiasis. Mayo. Clin. Proc. 83, 10:1154-9.

Sethi, S, Sehgal, R, Malla, N, Dubey, ML, Mahajan, RC, 2000: Changing trends of parasitic infections in Chandigarh (Northern India): Hospital based study. Indian J. Med. Microbiol. 18, 3:106-9.

Stevenson, RD, 1987: Mechanisms of anti- inflammatory action of glucocorticoids. Lancet $1: 225$.

Weber, R, Bryan, RT, Schwartz, DA, Owen, RL, 2006: Human Microsporal infections. Clin. Microbiol. Rev.7, 4:426-31.

Xiao, L, Bern, CI, Sulaiman, M, Lal, AA, 2004: Molecular epidemiology of human cryptosporidiosis. In R.C.A. Thompson (ed.), Cryptosporidium: from Molecules to Disease. Elsevier, Amsterdam, the Netherlands.

Zabolinejad, N, Berenji, F, Eshkaftaki, E B, Badeii, Z, Banihashem,A, et al, 2013: Intestinal parasites in children with impho- hematopoietic malignancy in Iran, Mashhad Jundishapur J. Microbiol. 6, 6:65-77. 